\title{
Evolução do Pronaf Crédito no Período 1996-2013: redimensionando o acesso pelos cadastros de pessoa física ${ }^{1}$
}

\author{
Adinor José Capellesso², Ademir Antonio Cazella ${ }^{3}$ e Fábio Luiz Búrigo ${ }^{4}$
}

\begin{abstract}
Resumo: As análises sobre o Programa Nacional de Fortalecimento da Agricultura Familiar (Pronaf), política pública de crédito rural, mobilizam, em sua maioria, os valores aplicados e o número de contratos como indicadores quantitativos de desempenho. Evidências empíricas apontam para uma elevada incidência de estabelecimentos familiares (EF) com mais de um contrato de Pronaf no mesmo ano. O presente trabalho emprega como indicador o Cadastro de Pessoa Física (CPF) dos beneficiários para demonstrar que o acesso é bem inferior ao apontado pelos números de contratos. Em 2013, foram computados 2.099.279 contratos de Pronaf, número que equivale a 48\% dos EFs cadastrados pelo Censo Agropecuário de 2006. Quando o acesso é medido pelos CPF, esse número cai para 1.154.613 tomadores, o que equivale a apenas $26 \%$ dos EFs recenseados. Em termos de concentração de recursos, o valor médio financiado por CPF registra forte crescimento a partir de 2008, o que fica parcialmente ocultado se o indicador for o valor médio dos contratos. Conclui-se que a avaliação da eficácia do Pronaf por meio da quantidade de CPF é mais precisa do que o número de contratos, constituindo-se em indicador relevante para aprimorar as análises sobre o alcance social desta política pública.
\end{abstract}

Palavras-chaves: sobreposição, beneficiários, indicador, exclusão, agricultura familiar.

Abstract: The analysis about the National Program for Strengthening Family Agriculture (Pronaf) in Brazil generally mobilize the amounts applied and the number of contracts as quantitative performance indicators. The empirical evidence points to a great overlap in this indicator, the existence of family establishments (EF) with more than one Pronaf contract in the same year. The present study uses the indicator of the beneficiary's CPF (Individual Taxpayer Registration Number) to demonstrate that access is well below that indicated by the number of contracts. In 2013, 2,099,279 Pronaf contracts, equivalent to 48\% of the EF registered in the 2006 Census of Agriculture, were

1. Data de submissão: 25 de maio de 2017. Data de aceite: 29 de outubro de 2017.

2. Instituto Federal de Educação, Ciência e Tecnologia de Santa Catarina. São Miguel do Oeste, Santa Catarina, Brasil.E-mail: adinor.capellesso@ifsc.edu.br

3. Universidade Federal de Santa Catarina. Florianópolis. Santa Catarina. Brasil. E-mail: ademir.cazella@ufsc.br

4. Universidade Federal de Santa Catarina. Florianópolis. Santa Catarina. Brasil. E-mail: fabio.burigo@ufsc.br 
computed. When access is measured by the CPF, this number drops to 1,154,613 insured persons, which is equivalent to only $26 \%$ of the registered in terms of concentration of resources, the average value financed by the CPF registered strong growth in relation to 2008, which is partially hidden if the indicator IS the average value of the contracts. It is concluded that the evaluation of the effectiveness of Pronaf based on the number of CPFs is more precise than the number of contracts, constituting a relevant indicator to improve the analysis of its social reach.

Key-words: overlap, beneficiaries, indicator, exclusion, family farming.

Classificação JEL: Q18.

DOI: http://dx.doi.org/10.1590/1234-56781806-94790560305

\section{Introdução}

Desde a sua criação, em 1996, o Programa Nacional de Fortalecimento da Agricultura Familiar (Pronaf) vem se constituindo na principal ação pública direcionada aos agricultores familiares brasileiros (SCHNEIDER, MATTEI e CAZELLA, 2004). Em sua origem, essa política pública pretendia atender a parcela de agricultores classificados como "aptos" à transição modernizante (GUANZIROLI et al., 1994; PETERSEN, 2013). Embora tal concepção estivesse explícita nos documentos que orientaram a formulação do programa, o tema foi retomado no debate acerca da viabilidade econômica dos Estabelecimentos Familiares (EF) de reduzido Valor Bruto de Produção agropecuária (VBPa). O aprofundamento da visão setorial do Pronaf e do debate sobre sua pertinência para atender agricultores que não estejam inseridos em sistemas produtivos de alto valor comercial é uma questão controversa. Uma posição extrema formulada por Alves e Rocha (2010) recomenda aplicar políticas de cunho social para essa parcela de agricultores familiares e não as de crédito produtivo oferecidas pelo Pronaf e outros programas do Sistema Nacional de Crédito Rural (SNCR).

Durante os mandatos do presidente Lula foram efetuados diversos ajustes no Pronaf com o propósito de democratizar a aplicação de seus recursos. Contudo, o acesso ao programa continua desigual e insuficiente face ao universo e ao perfil do público potencialmente beneficiário. Além de problemas de natureza institucional, que dificultam que os serviços de assistência cheguem de maneira abrangente aos agricultores familiares mais pobres, nota-se que suas verbas continuam primordialmente dirigidas para os sistemas de agricultura integrados às cadeias produtivas mais dinâmicas sob o ponto de vista produtivo e econômico, empreendidas, especialmente, na região Sul do País (ZANI e DA COSTA, 2014; CAZELLA e BÚRIGO, 2014; AQUINO e BASTOS, 2015; CAPELLESSO, CAZELLA e ROVER, 2016).

Apesar das tentativas de romper com esse padrão, a operacionalização do Pronaf adotou, na sua essência, a mesma dinâmica do SNCR, erigido desde o final dos anos 1960. Em certo sentido, pode-se dizer que, ao longo da sua trajetória, o Pronaf incorporou a lógica que orientou o processo de modernização conservadora do campo brasileiro (AQUINO e SCHNEIDER, 2010; GRISA, 2012; GRISA et al., 2014). Desse modo, os recursos do Pronaf atendem essencialmente as commodities milho, soja e café vinculadas, em boa parte, a mercados de exportação. Menos de 30\% dos montantes de custeio liberados priorizam cultivos de consumo interno - trigo, mandioca, arroz, feijão e outras produções típicas de explorações familiares, como hortas, pomares e pequenos animais (GAZOLLA e SCHNEIDER, 2013; GRISA et al., 2014).

Os recursos do Pronaf sempre foram direcionados na sua maior parte ao custeio agrícola. Contudo, nos últimos anos observa-se o crescimento dos valores aplicados em contratos de custeio pecuário e de investimento. Nesse último evidencia-se uma redução relativa nos valores direcionados ao "melhoramento das explorações", que envolve bens e serviços para qualificação da infraestrutura, enquanto cresce o montante aplicado em máquinas e equipamentos (SOUZA et al., 2013; GRISA et al., 2014). Essas aplicações se destinam, 
na sua maioria, à modernização do parque de máquina e aquisição de animais por parte de agricultores integrados às cadeias dinâmicas de valor. Elas representam a principal explicação para a concentração dos recursos do Pronaf nos estados e regiões onde a agricultura familiar se caracteriza por gerar elevado valor bruto de produção (SOUZA et al., 2010; CALSAVARA e CRUZ, 2013).

Por sua vez, a linha de microcrédito do programa (Pronaf B), classificada como investimento, alcançou o pico de $15 \%$ do total de recursos liberados em 2012 e entre $20 \%$ e $50 \%$ do total de contratos anuais efetuados nos últimos dez anos. Apesar de sua relevância, pois beneficia agricultores tradicionalmente excluídos do crédito rural, sua participação é ainda reduzida em relação ao conjunto da agricultura familiar que potencialmente demanda esse tipo de recurso. Além disso, as verbas do Pronaf B foram disponibilizadas sem atentar aos preceitos de programas internacionais de microcrédito bem-sucedidos, nos quais a proximidade do serviço financeiro com o tomador é considerada uma estratégia decisiva para o sucesso da operação. ${ }^{5}$ Sem o acompanhamento de um agente de crédito, a probabilidade da maioria dos contratos de microempréstimos se tornar inadimplente é muito elevada. Os tomadores do microcrédito não são capazes de modificar sozinhos a estrutura produtiva, nem de gerenciar as atividades de modo a elevar os ganhos de renda (MAIA et al., 2012).

Mesmo com as melhorias no acesso proporcionados pelos incrementos do Pronaf B, o nível de exclusão do programa continua elevado (CAPELLESSO e CAZELLA, 2015). Este trabalho tem por objetivo dimensionar o grau de acesso ao Pronaf crédito a partir de um novo indicador, que reduz os erros de superestimação: os dados do número de Cadastros de Pessoa Física (CPF) que acessaram o programa. Tendo como referência o período entre 1996 e 2013, a pesquisa cruza números oficiais de aplicação do Pronaf no País com informações obtidas em pesquisa empírica efetuada em EF localizados no extremo-oeste catarinense (EOC).

$\mathrm{O}$ artigo está estruturado em três partes, além desta introdução. A primeira descreve a metodologia,

5. A elevada inadimplência do Pronaf B explica, em grande parte, a criação do programa Agroamigo pelo Banco do Nordeste, o qual conta com a figura do agente de crédito. Algumas análises realizadas após essa reorientação do programa apontam para uma redução importante da inadimplência (ABRAMOVAY, 2008; CAZELLA e BÚRIGO, 2009; ALVES, 2015) com ênfase na forma como os dados foram sistematizados. A segunda emprega dados nacionais e regionais referentes às aplicações em crédito rural do Pronaf, comparando-os com os números de contratos e de CPF. Nesse tópico apresenta-se uma segmentação dos dados segundo as finalidades de uso do crédito e a sua expressão em relação ao número de EF existentes nas regiões e no País. Nas considerações finais apresentam-se ponderações quanto ao novo indicador de acesso ao Pronaf, indicando questões a serem aprofundadas em futuros estudos sobre o tema.

\section{Metodologia}

A primeira etapa da pesquisa consistiu em uma revisão de literatura sobre o desempenho do Pronaf. A partir de evidências empíricas sobre o fenômeno de sobreposições constatada em estudo de caso realizado no oeste catarinense, decidiu-se analisá-la em escala nacional. Para instrumentalizar a análise sobre o acesso ao Pronaf, buscou-se, junto ao Banco Central do Brasil (BCB), informações referentes ao período 1996-2013. Os dados obtidos se referem aos números de contratos efetuados, quantidades de CPF beneficiados e montantes financiados pelo Programa nas cinco regiões brasileiras. Além desses dados, para o intervalo compreendido entre 2004 e 2013, o BCB também forneceu informações, para as escalas regionais, por finalidades dos empréstimos e por tipo de atividades financiadas.

Por se tratar de uma série histórica, os valores nominais foram deflacionados pelo Índice Geral de Preços Disponibilidade Interna (IGP-DI), da Fundação Getúlio Vargas, tendo por base 100 o ano de 2013.

No tratamento dos dados do BCB, a quantidade de CPF beneficiada foi calculada subtraindo-se os casos em que o mesmo número aparece mais de uma vez, ou seja, em novo(s) projeto(s) contratado(s) no mesmo ano, o que se considerou se tratar de sobreposição. Ou seja, a realização de mais de um contrato de crédito por um mesmo produtor ao longo do ano. Posteriormente, essa sobreposição foi dimensionada a partir de uma relação obtida pela divisão da quantidade de contratos pela quantidade de CPF (1):

$$
\text { Sobreposição }=\frac{\sum \text { contratos }}{\sum C P F}
$$


O cálculo do valor médio das operações se deu pela divisão simples do somatório de recursos pelo número de contratos ou de CPF nas distintas escalas (2):

$$
\text { Valor médio }=\frac{\sum V D}{\sum X}
$$

Em que:

$\Sigma=$ somatório

$V D=$ valor de recursos liberados;

$X=$ quantidade de CPF ou de contratos.

Para avaliar o grau de acesso optou-se por apresentar comparativamente os gráficos construídos com base em números absolutos e, principalmente, em termos relativos $(\%)$, tendo como universo o total de EF cadastrados pelo Censo Agropecuário de 2006. Da mesma forma calculou-se o acesso relativo por finalidades de uso do crédito (3):

Acesso relativo ao Pronaf $(\%)=\left(\frac{\sum X}{\sum E F}\right) \cdot 100$

Em que:

$X=$ quantidade de CPF ou de contratos;

$E F=$ quantidade de estabelecimentos familiares recenseados em 2006.

Para dimensionar a sobreposição no uso do Pronaf nas escalas nacional e regional, os números de contratos e de CPF, bem como o montante absoluto de recursos, foram ponderados pela quantidade de EF pelo Censo Agropecuário de 2006. Embora esse último parâmetro não contemple as variações para mais ou para menos no número de estabelecimentos agropecuários ao longo do tempo, inexistem no Brasil dados cadastrais que permitam quantificar com precisão o número de estabelecimentos agropecuários. A apresentação desses dados, a seguir, está segmentada em duas partes: a primeira demonstra a sobreposição e as possibilidades de reinterpretação propiciadas pelo uso da quantidade de CPF como indicador de acesso, e a segunda destina-se a comparar e discutir os dados de acesso nas regiões brasileiras, levando-se em conta o número de EF.

\section{As sobreposições de contratos e o número de CPF como indicador de acesso}

Ao longo dos últimos 20 anos, o Pronaf tornou-se a política pública setorial de maior expressão junto aos agricultores familiares do País. A Figura 1 demonstra as evoluções desde as primeiras aplicações em 1996 até 2013.

Nota-se que, durante os mandatos do presidente FHC, o Pronaf passou por oscilações, seguidas de um período de estabilidade, registrando-se um crescimento atípico nos valores em 2002. No governo Lula (2003-2010), após uma breve retração inicial, o Pronaf registrou um constante crescimento nos montantes

Figura 1. Evolução do Pronaf, em valores* no Brasil (1996-2013)

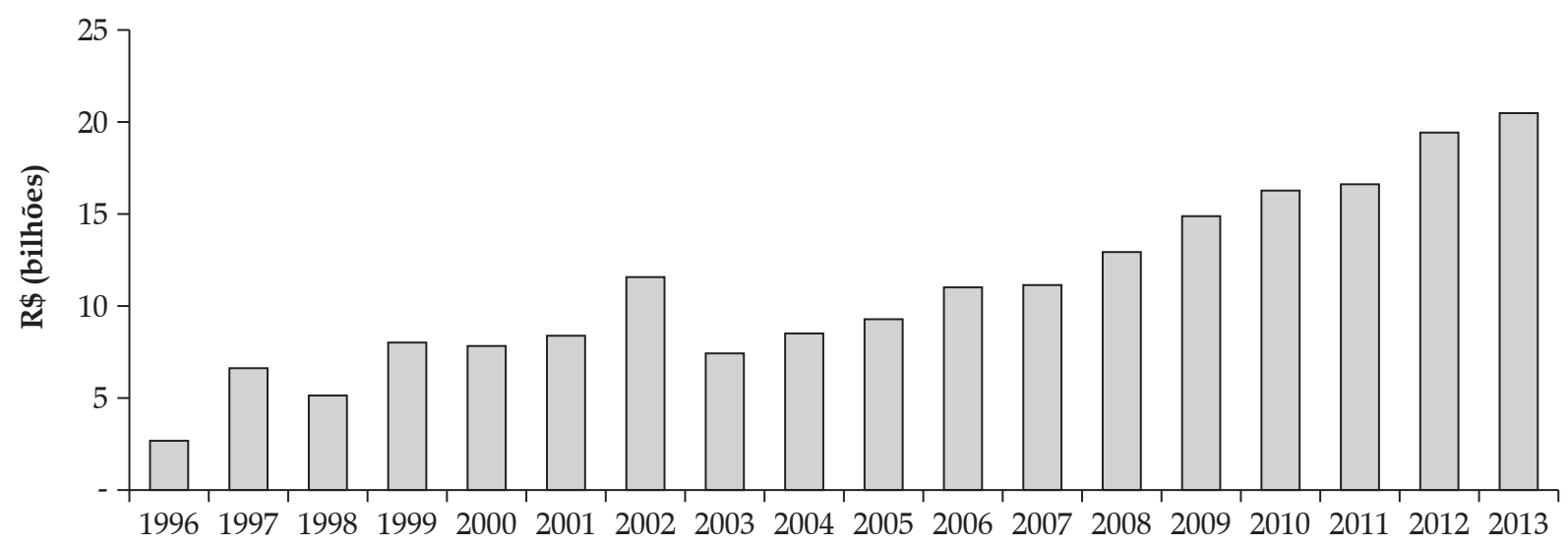

* Deflação pelo IGP-DI, com base 100 em 2013.

Fonte: Elaboração própria, a partir de dados do BCB (2014). 
liberados, comportamento que continuou nos primeiros anos do governo Dilma. No entanto, conforme se vê na Figura 2, essa evolução não ocorre com a mesma intensidade em relação ao número de beneficiários. Observa-se, por meio do número de contratos, que o acesso ao Pronaf teve seu auge em 2006, seguido de queda, e que somente em 2012 se observa um novo aumento. Segundo Souza et al. (2013), o crescimento registrado entre 2003 e 2006 é explicado pela liberação de financiamentos que estavam contingenciados pela falta de garantias, especialmente da linha Pronaf B, na maioria no Nordeste.

Se o acesso ao Pronaf é medido pelo número de CPF beneficiados, pode-se constatar que o seu alcance foi significativamente menos expressivo. Tendo como exemplo o ano de 2013, o Pronaf registrou 2.099.279 contratos. Ao se levar em conta o total de EF cadastrados pelo Censo Agropecuário de 2006 (4.367.902), e considerando que cada EF beneficiado pelo Pronaf tivesse efetuado apenas um contrato, o programa teria alcançado $48 \%$ do seu público potencial. Quando seu alcance é calculado, no entanto, pelo total de CPFs beneficiados no mesmo ano, o número de contemplados cai para 1.154.613. Ou seja, para 26\% dos EFs existentes no País em 2006 (BANCO CENTRAL DO BRASIL, 2014; IBGE, 2009).

Em termos de evolução, entre 2003 e 2006 verifica-se que o nível de acesso nacional ao Pronaf, medido pelo CPF, saltou de 796.325 para 1.476.807. Em bases percentuais, esse crescimento foi de fato elevado (mais que $85 \%$ ), mas bem inferior aos $151 \%$ registrados pelas abordagens que medem o acesso pelo número de contratos. A partir de 2006, o Pronaf enfrentou queda contínua no acesso calculado pelo CPF, que perdurou até 2011. Posteriormente, ocorreu uma retomada que, em 2013, situou-se ainda 21,8\% abaixo do patamar alcançado em 2006.

A análise da sobreposição ( $\Sigma$ contratos/ $/ \mathrm{CPF}$ ) tem redução gradativa até 2002, quando assume um comportamento ascendente até 2006. Após esse ano, constata-se um novo período de queda até 2008. Desde então, se amplia a média de contratos por agricultor, com maior intensidade entre 2011 e 2013. Esse dado reforça as conclusões de estudos que apontam a concentração do Pronaf em um grupo mais especializado de produtores (SOUZA et al., 2010; CALSAVARA e CRUZ, 2013). Nesse período, embora a quantidade de contratos indique elevação de $34,7 \%$ no acesso, a análise pelos CPFs redimensiona novamente essa expansão para níveis bem inferiores (14,9\%). Essa oscilação na curva de sobreposição sugere que o grau de acesso ao Pronaf é muito divergente quando medido pelos dois critérios.

A sobreposição de contratos do Pronaf pode induzir a associar-se sua maior frequência em EFs consolidados. E ao se concentrar nesse tipo de estabelecimento, o fenômeno seria maior no Sul e no Sudeste. Contudo, os dados do BCB apontam que o fenômeno também ocorre nas demais regiões. Ao segmentar os números em escalas regionais (Figura 3), verifica-se que o Nordeste registrou as maiores sobreposições e oscilações no período 1996-2008, e que as demais curvas de sobreposição pra-

Figura 2. Acesso ao Pronaf crédito no Brasil, pelo número de contratos e de CPF (1996-2013)

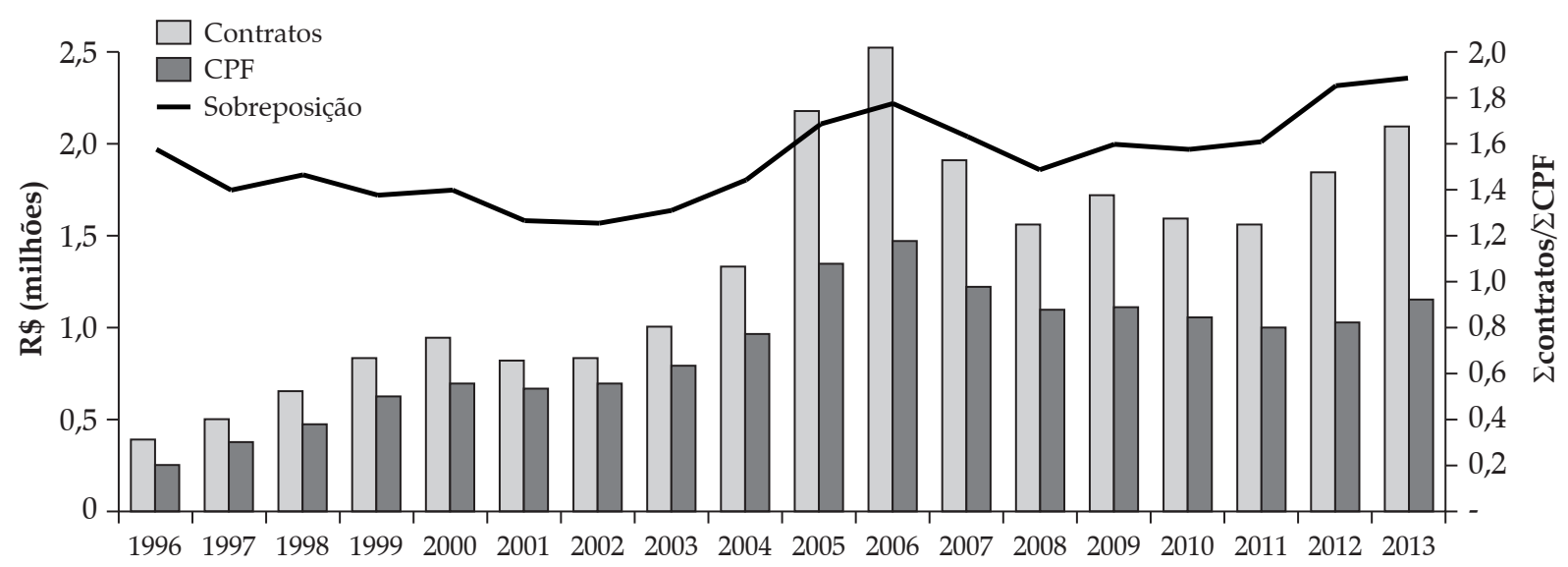

Fonte: Elaboração própria, a partir de dados do BCB (2014). 
Figura 3. Evolução da relação entre o número de contratos e o número de CPF (sobreposição) de beneficiários do Pronaf para as cinco regiões e para o Brasil (1996-2013)

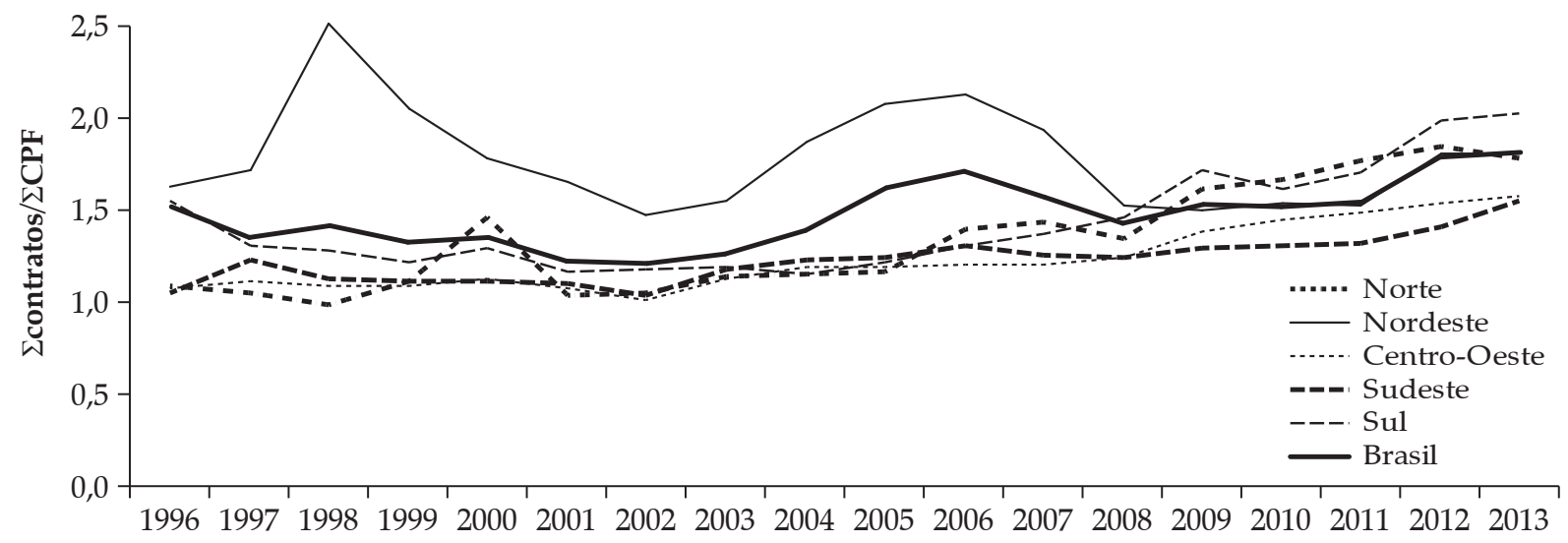

Fonte: Elaboração própria a partir de dados do BCB (2014).

ticamente se sobrepõem à registrada no Sul. A partir de 2006, a sobreposição cai no Nordeste e começa a crescer nas demais regiões, registrando, em 2013, mais expressão no Sul e no Norte. Essas duas regiões têm, respectivamente, o maior e o menor percentual de potenciais beneficiários atendidos pelo Pronaf, medidos pela relação entre CPF e EF recenseados.

A principal razão pela qual a sobreposição se manifestou inicialmente no Nordeste pode estar associada às barreiras de acesso até então existentes. Primeiramente, enquanto os agricultores menos capitalizados enfrenta- vam dificuldades para firmar contratos, os agricultores com maior capacidade de oferecer garantias aos agentes bancários acabavam firmando mais de um contrato por ano. Por sua vez, quando o agricultor menos capitalizado conseguia aprovar seu contrato, aproveitava para firmar outros de seu interesse.

A sobreposição de contratos reflete também no valor médio dos financiamentos do Pronaf, o que fica parcialmente distorcido quando se faz esse cálculo usando o número de contratos, em especial, entre 2008 e 2013 (Figura 4).

Figura 4. Valor médio dos empréstimos de Pronaf no Brasil, por números de contratos e números de CPF (1996-2013)

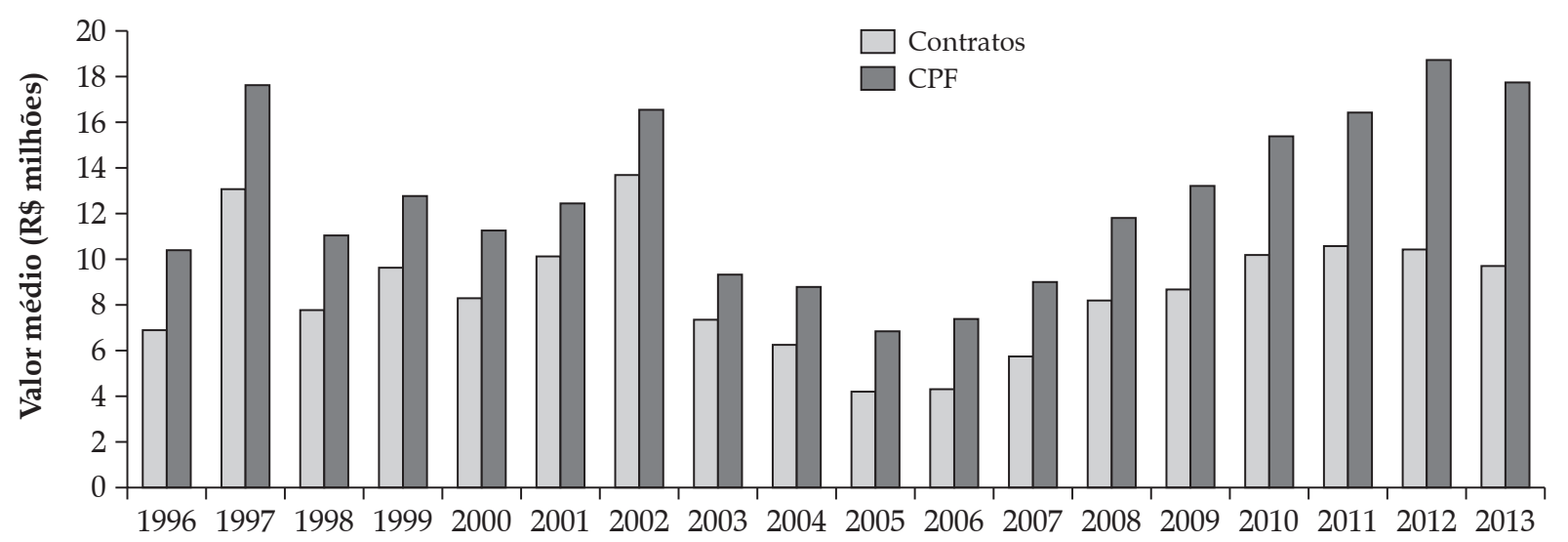

* Deflação pelo IGP-DI, com base 100 em 2013.

Fonte: Elaboração própria a partir de dados do BCB (2014). 
Figura 5. Valor médio dos empréstimos de Pronaf por região do Brasil, por números de CPF (1996-2013)

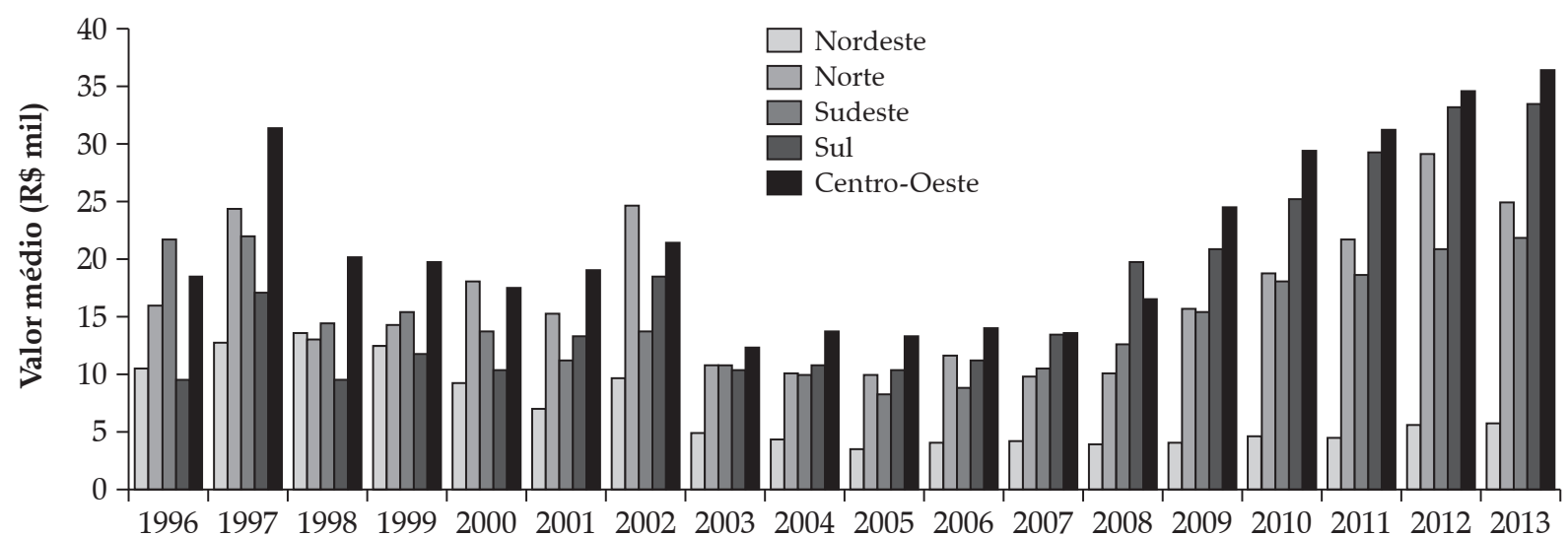

* Deflação pelo IGP-DI, com base 100 em 2013.

Fonte: Elaboração própria a partir de dados do BCB (2014).

A partir de 2008 eleva-se a diferença entre os dois tipos de valor médio na mesma proporção da sobreposição, pois trata-se de uma comparação entre médias simples. Observa-se que o maior valor médio por $\mathrm{CPF}$ ocorre em 2012 (R\$ 18,7 mil), sendo 6,0\% superior ao valor registrado em 1997 (R\$ 17,6 mil). Esse fenômeno coincide com o auge do Mais Alimentos, sendo que o valor médio seria ainda maior em ausência do Pronaf B, na época operado via metodologia Agroamigo. A inclusão dessa linha subestima o valor médio, como pode se observar no período 2003 até 2008, mas não foram encontrados dados segmentados para apurar a análise. Destaca-se que esse período coincide com a tentativa do Ministério do Desenvolvimento Agrário de forçar a ampliação do microcrédito, sendo a oscilação associada a inadimplência.

Ao segmentar esses dados em regiões, o Centro-Oeste apresenta o maior valor médio, seguido pelo Sul, Sudeste e Norte (Figura 5). A maior diferença ocorre em relação ao Nordeste, especialmente, a partir de 2003. Como esse período coincide com a expansão do Pronaf B, de menor valor, a queda no valor médio nacional se explica pela expressiva liberação dessa linha de crédito na região (GRISA et al., 2014). ${ }^{6}$ Em menor proporção, esse fenômeno também ocorre nas demais regiões entre 2003 e 2007, o que permite supor o crescimento no acesso de segmentos menos capitali-

6. Para detalhes explicativos dessa expansão, ver Grisa et al. (2014). zados em todo o País. A partir de 2008, mesmo com a retomada no número de contratos de Pronaf $\mathrm{B}$ registrada em 2009/2010, ocorre elevação no valor médio em todas as regiões, o que ficaria subestimado pela análise do valor médio dos contratos. ${ }^{7}$ Como já apontado, esse fenômeno tem relação direta com as liberações de contratos do Mais Alimentos.

O BCB também forneceu dados sobre a quantidade de CPF que acessaram crédito do Pronaf no Brasil por finalidade. Mas essas informações foram liberadas somente para o período 2004-2013. ${ }^{8}$ Pela Figura 6 pode-se visualizar a distribuição desse crédito pelas distintas finalidades, em números absolutos, bem como o acesso em termos relativos (\%), baseados nos EF recenseados em 2006. Os dados permitem apontar que, entre 2004 e 2006, o comportamento de ascensão registrado no âmbito nacional foi gerado pela ampliação do investimento pecuário - finalidade típica da maior parte dos contratos do Pronaf B. Já no investimento agrícola, a ampliação foi somente em 2012 e 2013. Como se verá adiante, essas oscilações nacionais nos investimentos agrícola e pecuário têm relação direta com a expansão que ocorreu no Sul e, especialmente, no Nordeste.

7. Em 2002, o Pronaf B liberava R\$ 500,00 por agricultor. Até 2013/14, esse valor se expandiu para R\$3.500,00, em valores não deflacionados.

8. O BCB informou limitações de pessoal para extrair diretamente do Sistema de Operações do Crédito Rural e do Proagro os dados relativos aos anos anteriores. 
Figura 6. Evolução da quantidade absoluta e relativa* de CPF com acesso ao Pronaf no Brasil, por finalidades (2004-2013)

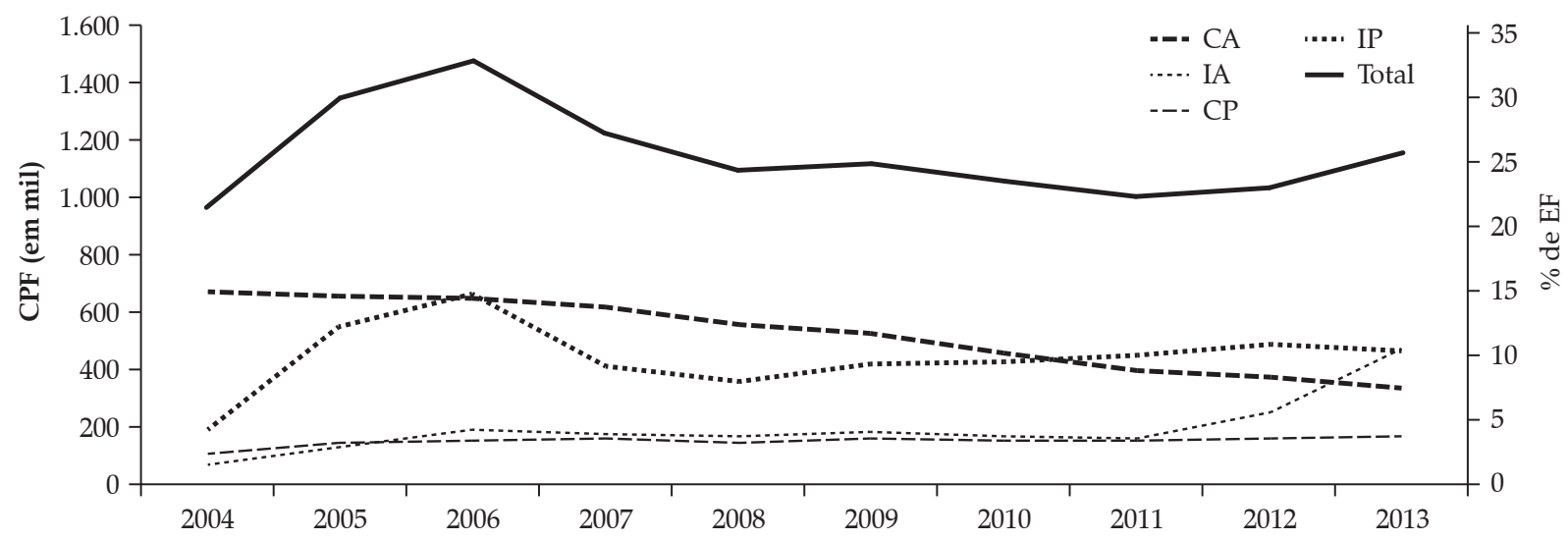

* Em relação aos Estabelecimentos Familiares (EF) cadastrados pelo Censo Agropecuário de 2006. Legenda: Custeio Agrícola (CA); Custeio Pecuário (CP); Investimento Agrícola (IA); Investimento Pecuário (IP).

Fonte: Elaboração própria a partir de dados do BCB (2014).

Os financiamentos destinados ao custeio pecuário registram estabilidade, enquanto o custeio agrícola vem perdendo número de acesso, o que reflete negativamente nas demais políticas públicas associadas ao crédito: a garantia de preços e o seguro agrícola. Levando-se em conta a quantidade de CPF, o percentual de beneficiários foi sempre inferior a $1 / 3$ do total de EFs cadastrados pelo Censo de 2006. Essa informação auxilia na avaliação sobre o alcance global do Pronaf em termos sociais, mas precisa ser mais bem analisada em distintas escalas.

\section{Comparações regionais ponderadas pela expressão da agricultura familiar}

Para aprofundar as análises de desempenho do Pronaf, tendo o CPF como critério de acesso, os dados do programa foram comparados às quantidades de EFs presentes nas cinco regiões brasileiras. Para isso, os dados foram inicialmente comparados em termos absolutos. Assim, por meio da Figura 7, pode-se observar que, entre 1996 e 2004, o Sul predominou no total

Figura 7. Evolução absoluta da quantidade de CPF com acesso o Pronaf para as cinco regiões brasileiras (1996-2013)

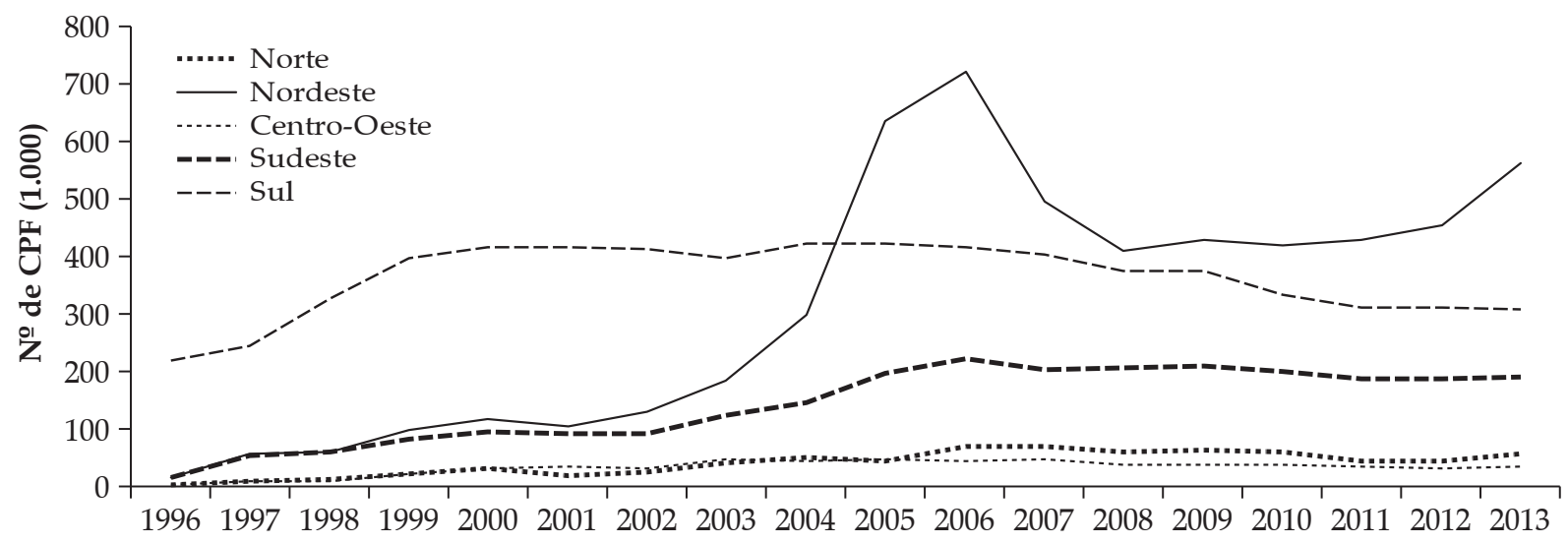

Fonte: Elaboração própria a partir de dados do BCB (2014). 
de CPFs beneficiados, sendo depois ultrapassado pelo Nordeste.

Todavia, quando o número de CPF é comparado ao total de EFs da respectiva região, revelam-se outros aspectos interessantes (Figura 8). Nos primeiros anos, o crescimento relativo do acesso ao Pronaf foi muito mais expressivo no Sul, embora tenha alcançado certa estabilidade entre 1999 e 2006. Ressalte-se que, nesta região, o programa sempre recebeu importante contribuição operacional das cooperativas de crédito e de agentes bancários com tradição em operar linhas de crédito rural (BÚRIGO, 2010). A partir daí, o acesso relativo no Sul entra em declínio, mais acentuado após 2009. Nas demais regiões, o crescimento de CPF beneficiados também ocorre nos primeiros anos, embora em muito menor escala. Essa evolução é positiva até 2006, quando também cessa, mas em patamares relativos bem inferiores aos alcançados pelo Sul. Após 2006, verifica-se uma tendência geral de queda, somente interrompida em 2011 e 2012.

A região Nordeste registra forte oscilação associada à tentativa de expandir o acesso ao Pronaf B após 2003. A falta de uma metodologia específica para trabalhar com agricultores de baixa renda contribuiu para elevar a inadimplência, o que deixou muitos desses agricultores impedidos de realizar novo acesso. A isso se soma a norma do Pronaf B que estabelece limite de três contratos com bônus de adimplência - desconto real no valor devido ao beneficiário que efetuar o pagamento dentro dos prazos -, muito valorizado pelos agricultores. Com o esgotamento dessa possibilidade, pode-se especular se os beneficiários dessa linha de financiamento deixaram de acessar ao crédito rural ou migraram para outra linha. Esse comportamento representa outra explicação para as oscilações no número de contratos do Pronaf B. De 2008 em diante há estabilidade no número de contratos, com nova elevação em 2012 e 2013, mas 32\% abaixo de 2006, ano de maior número de contratos em todo o período analisado.

Ao se comparar os dois gráficos anteriores percebe-se que, mesmo depois de 2005, quando assumiu a liderança em número absoluto de CPF beneficiados, o desempenho do Nordeste nunca se aproximou do Sul em relação ao montante de recursos e ao universo da agricultura familiar da respectiva região. Ou seja, embora o Pronaf B amplie o acesso, esse está longe de chegar ao público potencial classificado pelo Censo de 2006.

É importante frisar que muitas oscilações no desempenho do Pronaf não ficam tão claras quando se adota como critério de acesso o número de contratos (Figura 9). Como exemplos, a quantidade de contratos não evidencia a redução, após 2005, no número de acessos nas regióes Sul e Centro Oeste, comportamento bem diferente ao observado quando o acesso é calculado pelo número de CPF. Para o Nordeste, o número de contratos superestima a expansão verificada entre 2003 e 2005, bem como o revés registrado entre 2006 e 2008. Além disso, os valores percentuais

Figura 8. Evolução relativa da quantidade de CPF com acesso o Pronaf comparada ao número de estabelecimentos familiares* para as cinco regiões brasileiras (1996-2013)

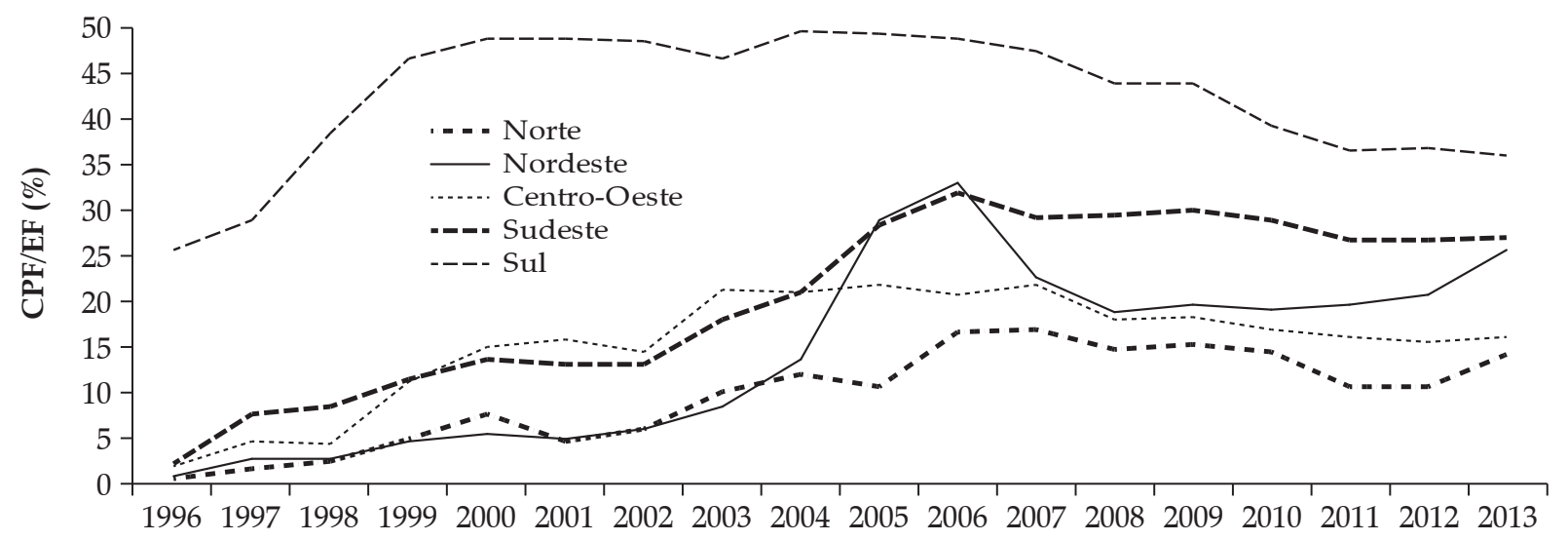

* Censo Agropecuário de 2006 (IBGE, 2009).

Fonte: Elaboração própria a partir de dados do BCB (2014). 
Figura 9. Evolução da quantidade de contratos do Pronaf em relação ao número de estabelecimentos familiares $(\mathrm{EF})^{*}$ para as cinco regiões brasileiras (1996-2013)

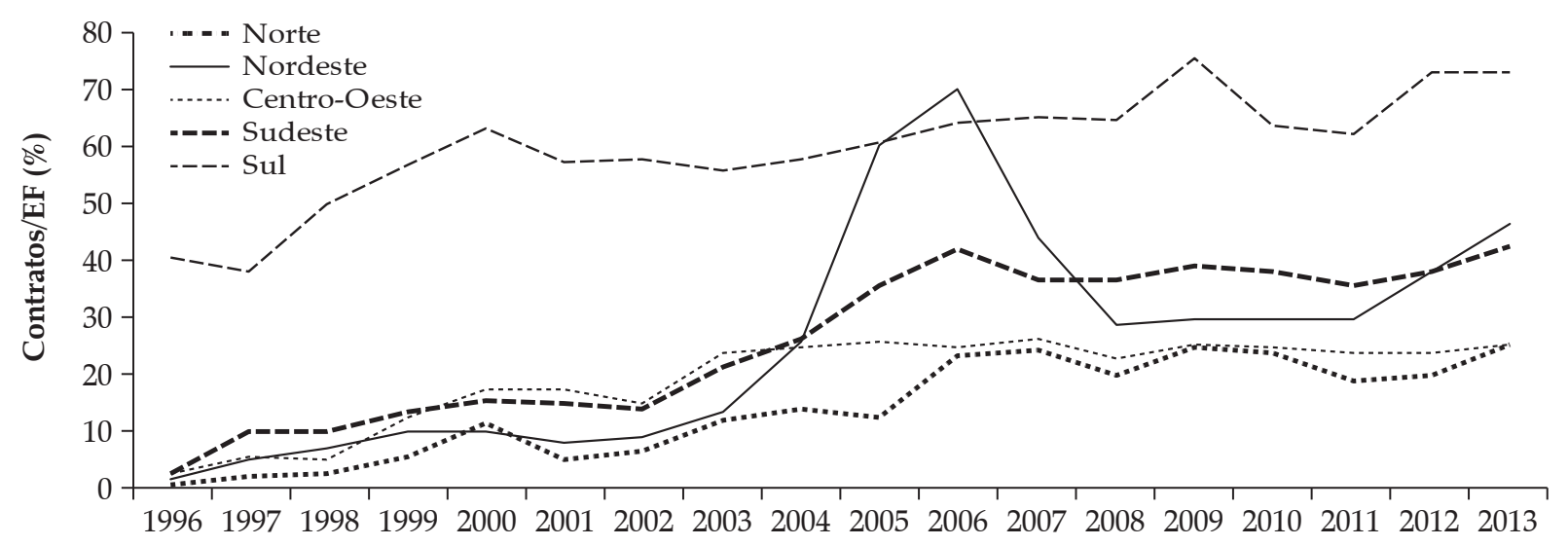

* Censo Agropecuário de 2006.

Fonte: Elaboração própria a partir de dados do BCB (2014).

em relação ao total de EF são sempre inferiores quando se analisa o nível de acesso pelo CPF.

Outra possibilidade de se analisar os dados de acesso ao Pronaf por CPF em termos regionais é pelas finalidades dos financiamentos. Por meio das diferentes partes que compõem a Figura 10 é possível visualizar as aplicações de programa no período 2004-2013, por finalidade.

Figura 10. Evolução relativa da quantidade de CPF com acesso às finalidades do Pronaf em relação aos estabelecimentos familiares* para as cinco regiões brasileiras (2004-2013)
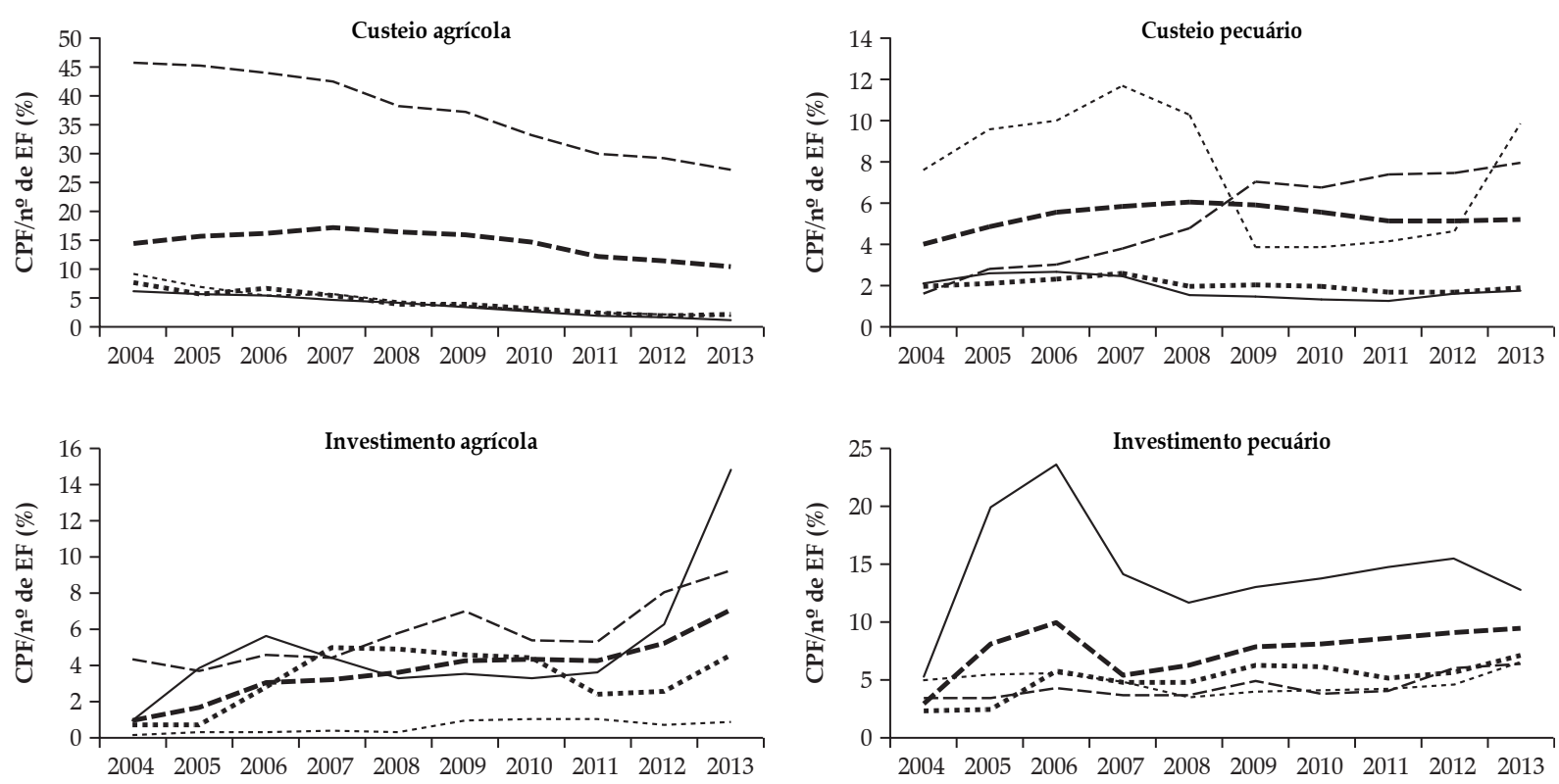

\#- Norte _- Nordeste ...... Centro-Oeste --.- Sudeste ---- Sul

* Com base nos dados do Censo Agropecuário de 2006. Nota: existem diferenças de escala no eixo vertical entre os gráficos.

Fonte: Elaboração própria a partir de dados do BCB (2014). 
Verifica-se que o Sul e o Sudeste alcançam maior percentual de beneficiários por meio do crédito de custeio, em que o uso do recurso restringe-se ao período aproximado de um ano. Já no Nordeste predomina o investimento destinado à pecuária, em que a duração do financiamento é bem maior. Embora um contrato de investimento tenha, por definição, duração de mais de um ano, o CPF ou a quantidade de contratos dos tomadores é contabilizado somente no ano da sua assinatura.

Os dados revelam, ainda, uma queda nos acessos ao custeio agrícola em todas as regiões do País. Como a duração desse tipo de contrato é quase sempre anual, a ausência do CPF nos dados do BCB significa que o agricultor deixou de fato de se beneficiar desse tipo de empréstimo. No caso da região Sul, onde esse tipo de financiamento tem maior expressão, tal queda é parcialmente contrabalançada com o aumento de beneficiários do custeio pecuário e do investimento, mas mesmo assim mantém-se a queda no total de acessos quando avaliado pelo número de $\mathrm{CPF}$.

Observa-se também que no custeio pecuário ocorreu uma oscilação expressiva nos dados do Centro-Oeste, que perdeu espaço entre 2009 e 2012, retomando sua importância relativa em 2013. Na região Sudeste destaca-se o gradativo crescimento nos investimentos. No Norte, o investimento agrícola tem oscilações, com elevações em 2006 e 2007, seguidas de quedas em 2011 e 2012. Por fim, o Nordeste diferencia-se pelo maior emprego relativo de investimento pecuário. Nessa região, as verbas destinadas à atividade agrícola crescem muito, mas somente a partir de 2011.

Outra forma de se abordar a evolução dos recursos do Pronaf por região é em relação aos montantes absolutos dessas aplicações (Figura 11). Embora venha perdendo espaço relativo frente ao valor global, o Sul ainda lidera a concentração dos recursos (SOUZA et al., 2013; GRISA et al., 2014). Essa condição reflete o elevado valor médio combinado ao alto número de acessos. No Nordeste, ainda que predominem contratos de investimento, que geralmente apresentam cifras mais elevadas e prazos mais dilatados para liquidação, é relevante observar que os valores globais aplicados são inferiores aos das demais regiões.

Para o Centro-Oeste, embora os contratos tenham maior valor médio, esse contrasta com o número reduzido de produtores que de fato têm acesso, considerando-se o total de potenciais beneficiários. Algo semelhante ocorre na região Norte, onde reitera-se o baixo acesso. A principal diferença refere-se ao Nordeste, área na qual o elevado número de acessos caracteriza-se pelo baixo valor médio, mais evidente à medida que se expande a quantidade de acessos ao Pronaf B.

Para avaliar a eficácia do Pronaf, a análise do volume de recursos liberados por região pode ser sempre efetuada considerando-se o número de EF existentes (Figura 12). Ao dividir o valor global pelo número de EF recenseados em 2006 para cada região, chega-se a um valor médio caso todas as unidades produtivas

Figura 11. Evolução* dos recursos aplicados pelo Pronaf por região (1996-2012)

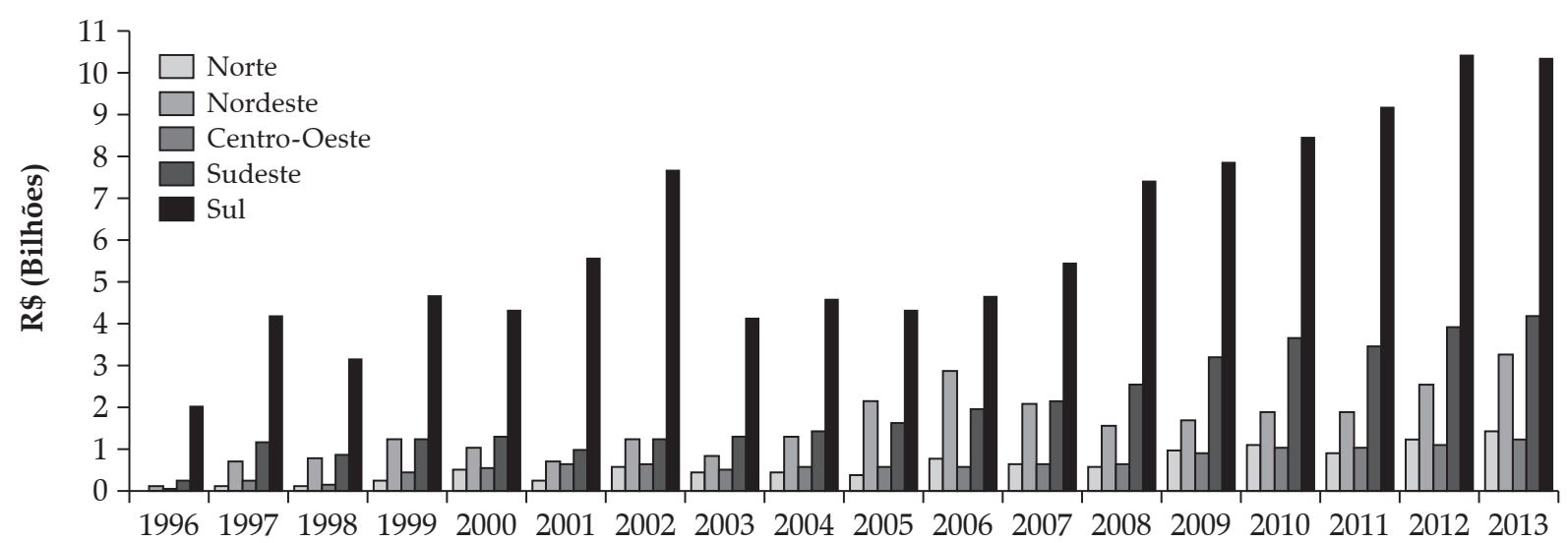

* Deflação pelo IGP-DI, com base 100 em 2013.

Fonte: Elaboração própria a partir de dados do BCB (2014). 
familiares tivessem acesso ao programa. Esses dados reiteram a concentração no Sul e reforçam a maior exclusão registrada no Nordeste, visto que o valor fica proporcionalmente ainda mais baixo. Mesmo com a ampliação do acesso via Pronaf $\mathrm{B}$ nessa região, esse ocorre por meio de contratos de baixo valor e continua longe de alcançar a maior parte do público potencial.

Os debates sobre inclusão no Pronaf de populações tradicionais que pouco representam em termos de VBPa apontam aspectos que precisam ser mais aprofundados, caso se deseje ampliar o espectro de beneficiários do programa. Nessa direção, Maia et al. (2012) verificaram que $82 \%$ das operações de Pronaf B acessadas via Banco do Nordeste destinaram-se à aquisição de animais, geralmente comprados com os propósitos de constituir uma "poupança" (devido à elevada liquidez) e/ou atender às necessidades de autoconsumo. Para esses autores, essa orientação visa aliviar a penúria dos beneficiários, mas dificilmente contribui com a estruturação produtiva e a melhoria da renda, que representa o objetivo principal dessa linha de crédito. Analisando as estratégias de reprodução socioeconômica de famílias rurais pobres no Rio Grande do Norte, Aquino e Lacerda (2014) destacam a heterogeneidade de causas da pobreza rural. Ao atacar somente uma dessas deficiências - o acesso ao crédito rural -, o Pronaf B necessitaria ser implantado de forma articulada com políticas de assistência técnica e de educação, bem como de acesso à terra, à água e às tecnologias. As deficiências desse arranjo institucional ampliam a dependência dos agricultores em relação aos ingressos provenientes de fora dos EF, tais como aposentadorias rurais e benefícios oriundos de políticas sociais.

\section{Conclusões}

O presente artigo dimensionou comparativamente o acesso ao Pronaf por meio da quantidade de contratos e de cadastros de pessoa física dos beneficiários. A análise evidencia que os estudos elaborados com base no número de contratos superestimam o público contemplado. Embora a quantidade de CPF também não reflita exatamente o número de estabelecimentos beneficiados, pois pode haver mais de um CPF contemplado em uma mesma unidade agrícola familiar, esse indicador de acesso demonstra com mais precisão o alcance do programa em termos sociais. Para exemplificar essa situação toma-se por base 2006, ano em que se registrou o maior número de contratos de Pronaf. O total de 2.528 .853 contratos firmados correspondia a 1.476.807 CPF de beneficiados, ou seja, um número de $42 \%$ inferior de acessos.

Esses dados permitem afirmar que o Pronaf está longe de contemplar o conjunto dos agricultores familiares brasileiros. Tendo em conta 2006, o número total de CPFs atendidos pelo programa corresponde a menos de $34 \%$ dos estabelecimentos agropecuários do País, contabilizados pelo último censo agropecuário de 2006. Em síntese, mesmo no ano de maior expres-

Figura 12. Relação entre montante global liberado* pelo Pronaf e a quantidade Estabelecimentos Familiares (EF) das regiões brasileiras

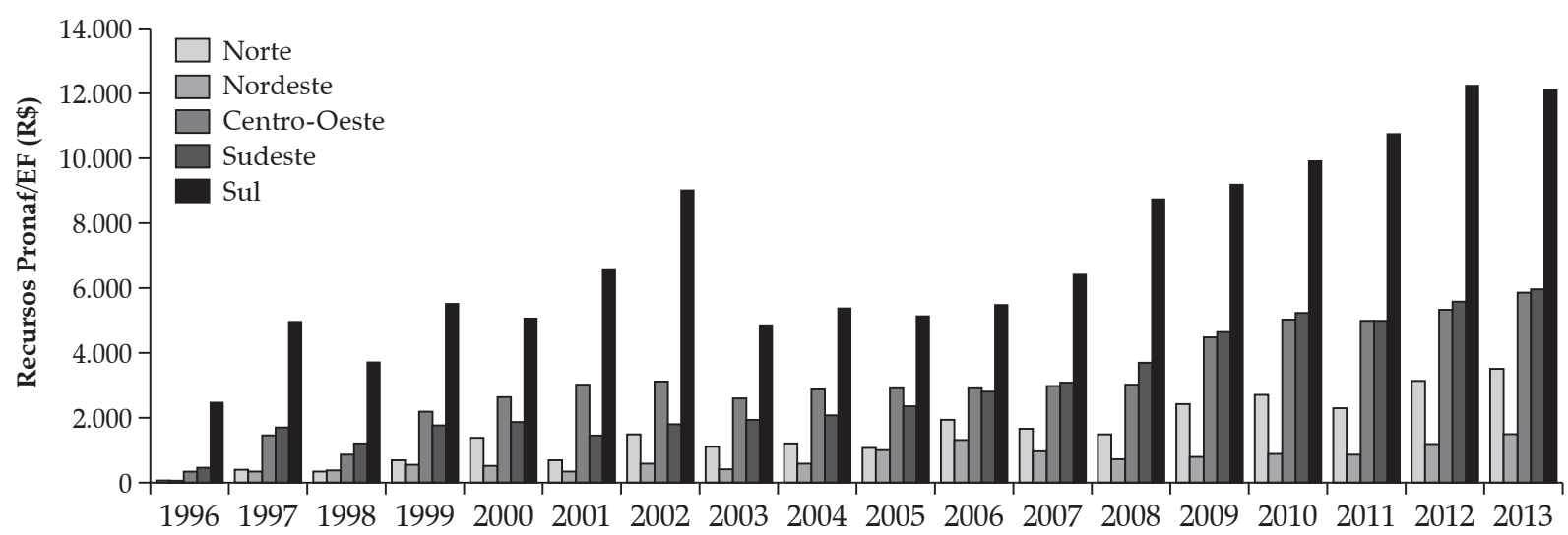

* Deflação pelo IGP-DI, com base 100 em 2013.

Fonte: Elaboração própria a partir de dados do BCB (2014). 
são nos acessos, o Pronaf alcançou somente 1/3 dos EFs nacionais, seus potenciais beneficiários.

Em grande medida, o elevado grau de exclusão reflete as ideias que orientaram a elaboração do programa, concebido para atender o público de agricultores familiares consolidados ou em transição modernizante. Logo, é conveniente questionar: seria uma distorção avaliá-lo na perspectiva da universalização no acesso, já que não era esse seu objetivo primordial? Se a resposta for que se trata de uma distorção, não é de se estranhar que o valor médio liberado por agricultor beneficiário venha crescendo, como fica mais evidente a partir de 2008. Esses dados corroboram a concentração dos recursos em commodities e na motomecanização, indicando a reprodução de ideias que orientaram a modernização conservadora.

O programa representa, na verdade, um estímulo da ação pública para integrar agricultores familiares aos mercados, havendo limitações para a construção de sistemas produtivos alternativos às cadeias tradicionais de valor. Como exemplo, ao focalizar um público geralmente alheio aos mercados globais, o Pronaf B encontra dificuldade de se constituir em mecanismo de estímulo à geração de renda. Nesse caso, "mais do mesmo" e "exclusão" expressam-se como resultado premeditado e não como consequência indesejada.

A análise detalhada do Pronaf pelo número de $\mathrm{CPF}$ reitera que o programa possui maior concentração de acessos e de recursos liberados nos EF da região Sul do País. Contudo, é relevante considerar que essa região perde expressão, especialmente, após 2007, com queda no número absoluto de beneficiários. Tal redução tem relação direta com a diminuição dos financiamentos destinados ao custeio agrícola, sobretudo quando as culturas financiadas têm baixo índice de perda, o que reduz a importância do seguro agrícola. Nesse caso, parte dos agricultores vem utilizando recursos próprios ou migrando para o custeio pecuário, condição que evita o pagamento do prêmio do seguro.

Na região Sul, enquanto caem os créditos para o custeio agrícola, os empréstimos destinados aos custeios e aos investimentos se expandem, especialmente, a partir de 2012. Como destacado acima, além de financiar a produção animal diretamente, $\mathrm{o} C \mathrm{CP}$ passou a financiar parte das áreas de milho para silagem, produto empregado na bovinocultura de leite.

As regiões Centro-Oeste e Norte destacam-se pelos baixos números de potenciais beneficiários atendidos pelo Pronaf. No Centro-Oeste os contratos têm, por sua vez, um valor médio bastante elevado. Já o Nordeste experimentou forte evolução no acesso ao programa, aproximando-se do Sudeste em termos relativos de potenciais beneficiários atendidos. Como esse crescimento do Pronaf no Nordeste ocorreu simultaneamente com uma redução do valor médio dos contratos, seus resultados são atribuídos à implantação do Pronaf B. Dentro dessa linha destaca-se o programa Agroamigo do Banco do Nordeste, que realiza uma política de proximidade com os beneficiários via agentes de crédito. Contudo, além de insuficiente em relação do público potencial, o acesso se confronta com a limitada capacidade institucional do Pronaf para combinar os seus recursos creditícios com medidas capazes de combater outros aspectos geradores da pobreza rural.

Não obstante esses limites institucionais e nos dados de desempenho do Pronaf, os recursos de (micro) crédito rural podem ser empregados visando beneficiar uma camada mais expressiva de EF, hoje distantes dos mercados mais dinâmicos. Para isso é necessário que esses incentivos estejam fortemente articulados a políticas de assistência técnica, a melhorias organizativas do público tradicionalmente excluído, e a outras ações de fortalecimento do ambiente institucional e produtivo da agricultura familiar. Ou seja, um conjunto de estratégias que o desenho atual do Pronaf e as demais políticas do SNCR não incorporam ou não conseguem efetivar em termos operacionais.

\section{Referências}

ABRAMOVAY, R. Alcance e limites das finanças de proximidade no combate à inadimplência: o caso do Agroamigo. Fipe, Texto para discussão, n. 10, 2008.

ALVES, M. O. O agroamigo e o público potencial do Pronaf b: uma análise do alcance a partir do cadastro socioeconômico. Rev. Econ. NE, Fortaleza, v. 46, suplemento especial, p. 161-176, jul. 2015

ALVES. E. e ROCHA, D. de P. Ganhar tempo é possível? In: GASQUES, J. G., VIEIRA FILHO, J. E. e NAVARRO, Z. (Orgs.). A agricultura brasileira: desempenho, desafios e perspectivas. Brasília: IPEA, 2010, p. 275-290.

AQUINO, J. R. e SCHNEIDER, S. (Des)caminhos da política de créditor do Pronaf na luta contra a pobreza e a desigualdade social no Brasil rural. In: I Conferência Nacional de Políticas Públicas contra a pobreza e desiguladade. Natal, 2010. 
AQUINO, J. R. e LACERDA, M. A. D. Magnitude e condições de reprodução econômica dos agricultores familiares pobres no semiárido brasileiro: evidências a partir do Rio Grande do Norte. Revista de Economia e Sociologia Rural, v. 52, suppl. 1, p. 167-188, 2014.

AQUINO, J. R. e BASTOS, F. Dez anos do Programa Agroamigo na região Nordeste: evolução, resultados e limites para o fortalecimento da agricultura familiar. Rev. Econ. NE, v. 46, suppl. especial, p. 137-158, jul. 2015.

BANCO CENTRAL DO BRASIL. Informações extraídas do Sistema de operação do crédito rural e do Proagro (Sicor). Novembro de 2014.

BÚRIGO, F. L. Finanças e Solidariedade: cooperativismo de crédito rural solidário no Brasil. Chapecó: Argos, 2010. 454p.

CALSAVARA, G. e CRUZ, A. C. Análise da concentração de recursos do Proanf. Sociedade e Desenvolvimento Rural, v. 7, n. 4, p. 74-91, nov. 2013.

CAPELlESSO, A. J., CAZELlA, A. A. e ROVER, O. J. Ambiguidade de referenciais tecnológicos da ação pública no meio rural: agricultura familiar e limites à sustentabilidade. Desenvolvimento e Meio Ambiente, Curitiba, v. 36, p. 167-187, abr. 2016.

CAZELLA, A. A. e BURIGO, F. L. Inclusão financeira e desenvolvimento rural: a importância das organizações territoriais. Política E Sociedade, v. 8, p. 301-331, 2009.

e BÚRIGO, F. L. Sistemas territoriais de financiamento rural: para pensar o caso brasileiro. Emancipação, Ponta Grossa, v. 13, n. 2, p. 297-312, 2014.

. e CAPELLESSO, A. J. As políticas públicas de apoio à agricultura familiar frente aos desafios da inclusão socioprodutiva: análise da experiência brasileira recente. In: Anais do XII Conlab, Lisboa, 2015.

GAZOLLA, M. e SCHNEIDER, S. Qual 'fortalecimento' da agricultura familiar? Uma análise do Pronaf crédito de custeio e investimento no Rio Grande do Sul. Revista de Economia e Sociologia Rural, v. 51, n. 1, p. 45-68, jan./ mar. 2013.

GRISA, C. Politicas públicas para a agricultura familiar no Brasil: produção e institucionalização das ideias. Tese
(Doutorado) Instituto de Ciências Humanas e Sociais, Universidade Federal Rural do Rio de Janeiro, 2012.

., WESZ JUNIOR, V. J. e BUCHWEITZ, V. D. Revisitando o Pronaf: velhos questionamentos, novas interpretações Revista de Economia e Sociologia Rural, v. 52, n. 2, p. 323-345, 2014.

GUANZIROLI, C. E. et al. Diretrizes de politica agrária e desenvolvimento sustentável. Brasília, DF: FAO/INCRA, 1994, 24p. (Versão resumida do Relatório Final do Projeto UTF/BRA/036).

IBGE - Instituo Brasileiro de Geografia e Estatística. Censo Agropecuário 2006: Brasil, Grandes macrorregiões e Unidades da Federação. Rio de Janeiro: IBGE, 2009.

MAIA, G. B. S. et al. O Pronaf B e o financiamento agropecuário nos Territórios da Cidadania do semiárido. Revista do BNDES, v. 37, p. 177-216, jun. 2012.

PETERSEN, P. Agroecologia e a superação do paradigma da modernização. In: NIEDERLE, P. A. et al.. Agroecologia: práticas, mercados e políticas para uma nova agricultura. Curitiba: Kairós, 2013, p. 69-103.

SCHNEIDER, S., MATTEI, L. e CAZELLA, A. A. Histórico, caracterização e dinâmica recente do Pronaf - Programa Nacional de Fortalecimento da Agricultura Familiar. In: SCHNEIDER, S., SILVA, M. K. e MARQUES, P. E. M. (Orgs.). Políticas públicas e participação social no Brasil rural. Porto Alegre, 2004, p. 21-50.

SOUZA, P. M., NEY, M. G. e PONCIANO, N. J. Comportamento da distribuição dos financiamentos do pronaf entre as unidades da federação, no período de período de 1999 a 2009. In: Anais do 48 Congresso da Sober, Campo Grade, 2010.

. et al. Análise da Evolução do Valor dos Financiamentos do Pronaf-Crédito (1999-2010): número, valor médio e localização geográfica dos contratos. Revista de Economia e Sociologia Rural, v. 51, n. 2, p. 237-254, abr./jun. 2013.

ZANI, F. B. e DA COSTA, F. L. Avaliação da implementação do Programa Nacional de Fortalecimento da Agricultura Familiar - novas perspectivas de análise. Revista Administração Pública, v. 48, n. 4, p. 889-912, jul/ ago. 2014 .

Todo o conteúdo deste periódico, exceto onde estiver identificado, está licenciado sob uma Licença Creative Commons (cc by 4.0). 